\title{
ДИСЦИПЛИНАРНАЯ ОТВЕТСТВЕННОСТЬ ОСУЖДЕННЫХ К ЛИШЕНИЮ СВОБОДЫ. ИСТОРИЧЕСКИЙ ОБЗОР
}

\begin{abstract}
Дядькин Дмитрий Сергеевич
доктор юридических наук, доцент, заведующий кафедрой уголовного права и процесса, директор Института государства и права

Сургутского государственного университета Ханты Мансийского автономного округа - Югры

Алиев Зияфат Гаджиевич кандидат юридических наук, старший преподаватель
\end{abstract}

Аннотация: Статья посвящена возникновению института «дисциплинарная ответственность осужденных к лишению свободы», его основным периодам развития, проблемам отечественного и российского уголовно-исполнительного законодательства в сфере привлечения осужденных к дисциплинарной ответственности, видам правонарушений и мерам взыскания, применявшимся к осужденным указанной категории.

Ключевые слова: осужденный, установленный порядок отбывания наказания, дисциплинарное нарушение, дисциплинарная ответственность, злостное нарушение установленного порядка отбывания наказания, меры взыскания, исправительно-трудовой кодекс.

\section{DISCIPLINARY RESPONSIBILITY OF PERSONS SENTENCED TO DEPRIVATION OF LIBERTY. HISTORICAL OVERVIEW}

Dyadkin Dmitry Sergeevich Aliyev Ziyafat Gadzhievich

\footnotetext{
Abstract: The article is devoted to the emergence of the institution "disciplinary responsibility of convicted persons to deprivation of liberty", its main periods of development, problems of domestic and Russian penal enforcement legislation in the field of bringing convicted persons to disciplinary responsibility, types of offenses and penalties applied to convicted persons of this category.
} 
Key words: convicted person, established procedure for serving a sentence, disciplinary violation, disciplinary responsibility, malicious violation of the established procedure for serving a sentence, penalties, correctional labor code.

Уголовно-исполнительное законодательство и уголовно-исполнительная практика, связанные с дисциплинарной ответственностью осужденных, в процессе истории отечественной пенитенциарной системы претерпевали серьезные изменения, обусловленные диалектическими процессами государственного и правового развития.

История возникновения дисциплинарной ответственности лишенных свободы находится в неразрывной связи с зарождением и развитием исправительных учреждений.

Дисциплинарная ответственность как вид юридической ответственности зарождается и формируется в России, впрочем, как и в Европе, в XIX столетии. Это становление неразрывно связано с вопросами развития исправительных учреждений, назначением которых являлось исполнение наказаний в виде лишения свободы.

Одним из основных видов исправительных учреждений России традиционно являлась тюрьма. Появление тюрем как мест лишения свободы в России относится к периоду середины XVI века. [1, с.46].

Тюрьма служила местом для помещения и содержания в ней лиц, либо ожидавших наказания за содеянное, либо отбывающих его. На более ранних стадиях существования исправительного дела тюрьма служила местом для временной изоляции лиц, ожидавших вынесения приговора, т.е. местом исполнения меры пресечения в виде содержания под стражей.

В дальнейшем, в период петровских преобразований, в связи с большим строительством и необходимостью для этого рабочей силы возникает новый вид наказаний - каторжные работы (1699 год), которые отбывались на галерах, в портах, рудниках, крепостях, на заводах и промыслах. [2, с.8].

Однако, несмотря на увеличение мест исполнения наказания в виде лишения свободы (тюрьмы, каторги), практически до середины XIX века внутренний распорядок в местах лишения свободы был нормативно не урегулирован. Отношения между персоналом учреждений и лицами, отбывающими наказания, складывались на естественной основе и зачастую определялись интуитивно на основании пенитенциарного опыта.

Дисциплинарная ответственность лиц, отбывающих наказание в виде лишения свободы, как вид юридической ответственности, т.е. основанный на 
документах законодательного характера, зарождается и формируется в России в XIX столетии. Первые попытки регулирования жизни заключенных в местах отбывания наказания предпринимались и ранее. К таковым можно отнести Инструкцию петербургской тюрьмы 1779 года, Положение о должности смотрителя тюремного замка в Москве (Бутырская тюрьма), Инструкцию о должности караульного офицера (1804 г.).

Попыткой систематизации актов в области тюремного законодательства более позднего периода можно считать принятие в 1828 году департаментом полиции России общей тюремной инструкции, определявшей правила поведения осужденных и устанавливающей запреты на брань, ссоры, игры в шашки, кости, пользование письменными принадлежностями. Сюда же относится и первое издание Устава о содержащихся под стражей (1832 г.).

Установленные запреты содержали в себе элементы юридической ответственности, так как охраняли правила, оговоренные в документе, регламентирующем поведение осужденных, и влекли за собой установленные этим актом юридические последствия в виде дисциплинарных взысканий.

В этот период, наряду с другими видами уголовных наказаний, все шире начинают применяться меры по изоляции правонарушителей от общества. Лишение свободы назначалось, как правило, за убийство, изнасилование, а также лицам, допустившим многократный рецидив преступлений.

В местах отбывания наказания создавалась обстановка полнейшей изоляции и тишины. Даже персонал тюрем, обеспечивающий это наказание, ходил по коридорам в тапочках, а колеса телег обматывались кожей, чтобы не создавать шума при езде по тюремному двору.

Для исполнения наказания в виде лишения свободы создавались и соответствующие камеры для одиночного содержания с полной шумоизоляцией. Эта мера уголовного наказания была одной из самых суровых, так как была основана на воздействии на психику осужденного и являлась бесчеловечной в силу того, что заканчивалась, как правило, психическими срывами узников, переходящими в психические заболевания различных форм и степени интенсивности. Естественно, надеяться на исправление осужденных в таких ситуациях было нельзя.

Следует отметить, что в отличие от европейской, российская исправительная система впитала в себя артельное содержание арестантов, что в целом предопределялось российским образом жизни того времени и некоторыми причинами экономического характера, так как строительство мест 
заключения значительно удешевлялось и не требовало дополнительных затрат на создание индивидуальных мест изоляции осуждённых.

В местах лишения свободы осужденный попадал в такие условия, которые значительно, а порой и коренным образом, отличаются от привычных условий жизни. Специфичность же условий определялась (и ныне определяется) режимом содержания отбывающих наказание. Режим содержания в исправительных учреждениях представлял собой свод правил, изложенных в тюремных инструкциях. Эти правила были обязательными для арестантов. Они имели свои специфические задачи: обеспечение изоляции от общества, надзор за осужденными, обеспечение контроля за точным соблюдением осужденными возложенных на них обязанностей; предупреждение нарушений дисциплины; недопущение совершения преступлений с их стороны и т.д. [3, с.162].

Перечисленные задачи поддерживались, как правило, мерами дисциплинарной ответственности лишенных свободы, которые, в свою очередь, различались по своей природе, в различные периоды становления и развития исправительной системы России были разнообразными.

Так, в XIX веке, в период наиболее интенсивного развития исправительной системы, существовавшие тюремные инструкции предусматривали целый ряд мер безопасности и дисциплинарной ответственности заключенных, нарушавших режим содержания. Отдельных, наиболее опасных преступников пересылали на Сахалин и в другие, отдалённые от центра регионы России. Появились запреты на назначение таких лиц на какие бы то ни было артельные должности в тюремной общине. На тех же, кто проявлял активное неповиновение персоналу тюрем, надевали смирительные пояса, наручники, кандалы либо наказывали розгами. В каторжных тюрьмах нарушителей вязали «утками» (руки и ноги вместе туго связывали на спине крепкой острорежущей веревкой таким образом, что скоро наступало онемение всего тела), [4, с. 38], приковывали к тачке, накладывали оковы, принудительно на лбу наносили татуированную надпись - «каторжный».

Помимо этого, к заключенным, нарушающим правила поведения, применялись и другие виды дисциплинарного воздействия. Для поддержания тюремной дисциплины использовались физическое воздействие либо изоляция от других арестантов.

Помимо этого распространены были различного рода ограничения в правах заключенных, например, их лишали права на свидания с родственниками или же права на получение передач. 
23 мая 1901 года в Устав о содержащихся под стражей 1832 года были внесены существенные изменения, касающиеся применения мер дисциплинарной ответственности, но дух, которым было проникнуто законодательство XIX века, остался прежним.

Существовавшее тюремное законодательство не регулировало всех вопросов дисциплинарного воздействия на осужденных, не определяло понятий проступков, не регламентировало порядка наложения взысканий, что, в свою очередь, порождало вольное толкование нормативных актов и их применение по своему субъективному усмотрению, зачастую во вред интересам службы с ярко выраженными элементами тюремного произвола.

Отсутствие единой тюремной законодательной базы порождало нормотворческое местничество в отдельно взятых регионах страны на уровне конкретных мест лишения свободы в виде издания различных инструкций, правил поведения и т.д. Так, например, в Петропавловской крепости действовали «Правила о содержании арестованных в Санкт-Петербургской крепости». В соответствии с этим документом комендант крепости пользовался неограниченным объемом дисциплинарных полномочий в отношении арестантов. Он мог заключать узника в темный, сырой карцер сроком до одной недели и возобновлять это наказание даже на следующий день. Властные полномочия позволяли ему без ограничения срока лишать заключенных права чтения книг, переписки, свиданий. [5, с.16].

Наиболее распространенной мерой дисциплинарного воздействия признавалось водворение в карцер. При этом в качестве карцеров применялись как специально подготовленные для этого помещения, так и обычные камеры, откуда изымались спальные принадлежности. Помещение в карцер следовало за самые различные нарушения дисциплинарного характера, такие как невставание при поверке, передача записок другим заключенным, перестукивание и т.п.

Применяемые меры дисциплинарного воздействия, носившие характер телесных мучений, осуждались большинством стран мира. Однако это положение, являясь некоторым сдерживающим фактором, не исключало практики применения физических истязаний, применяемых к заключенным.

Несмотря на то, что Парижский пенитенциарный конгресс (1895г.) высказался за необходимость отмены телесных наказаний, они по- прежнему были одними из основных дисциплинарных взысканий по пенитенциарному законодательству как России, так и большинства других европейских 
государств. [6, с.52]. В США существовал смирительный стул, в Англии девятихвостая кошка. [7, с.59].

Помимо Устава о содержащихся под стражей и Устава о ссыльных в начале XX века появляются новые нормативные акты в области пенитенциарной практики. К таковым актам относились: Инструкция смотрителя тюремного замка, просуществовавшая до 1901 года; Общая тюремная инструкция 1915 года; Особая инструкция для наблюдательных комиссий; Устав состоящих под высочайшим покровительством Санкт-Петербургских и Московских и благотворительных тюремных комитетов и многочисленные «приложения» к различным статьям уставов о содержащихся под стражей и ссыльных.

Тюремное законодательство начала XX века характеризовалось, наряду с прочим, и некоторыми послаблениями в режиме содержания арестантов.

Так, в 1903 году было отменено для ссыльнокаторжных и ссыльнопоселенцев бритье головы, наказание плетьми, приковывание к тележке, однако, применение розг как вид дисциплинарного наказания сохранялось до 1917 года.

Бессрочные каторжные содержались «в ручных и ножных оковах» в течение 8 лет.

Несколько другое правовое положение имели женщины-арестантки. В соответствии с законом от 1863 года женщины освобождались от телесных наказаний по суду, однако они не освобождались от них как от меры дисциплинарного воздействия.

Несмотря на произвол, царивший в тюрьмах по отношению к заключенным, указанная царская тюремная инструкция внушала работникам пенитенциарных учреждений не причинять заключенным никаких огорчений или каких-либо насилий под угрозой строжайших за то наказаний. Она требовала от тюремной администрации соблюдения правил религиозного толка, основанных на человеколюбии, одновременно принимать все меры для поддержания внутритюремной дисциплины. При решении вопроса о телесном наказании предписывалось принимать во внимание степень виновности, умственного развития и индивидуальной особенности арестанта, его нравственную чувствительность.

После Февральской революции 1917 года политика Временного правительства находила свое выражение, в основном, в отдельных декларациях. В приказе № 4 Главное управление тюрьмами осудило тюремный произвол и работавший в то время тюремный персонал, который оказался непригодным 
для осуществления задач внутреннего тюремного переустройства в связи с новым подходом к тюремному делу в целом. Временное правительство вынуждено было отменить такие виды дисциплинарных мер ответственности, как оковы, телесные наказания, смирительную рубашку, темный карцер.

Главная задача наказания, как указывалось в приказе руководителя Главного тюремного управления А.А. Жижиленко, - перевоспитание человека, имевшего несчастье впасть в преступление в силу особенностей своего характера или неблагоприятно сложившихся обстоятельств. [8, с.69]. Характеризуя исправительную систему того времени в целом, следует определить, что каких-либо существенных изменений как в организационном построении, так и в содержательном порядке она не претерпела. В основу брались все те же основные положения нормативных актов царского периода.

Однако во всей политике в области тюремного дела явно прослеживалась линия гуманизации применявшихся к заключенным мер, что в свою очередь воспринималось неоднозначно.

Что касается применения карцера, то Главное управление местами заключения определилось не сразу. В циркулярах № 50 от 5 июня 1917 года отмечалось, что согласно от 28 мая 1916 года во многих тюрьмах были намечены устройство новых и капитальный ремонт существовавших карцеров, а также приспособление под карцеры некоторых помещений и предлагалось ввиду предстоящего пересмотра Общей тюремной инструкции воздержаться от обеспечения мест заключения карцерами и приостанавливать начатые работы. $[9$, c.24].

Анализ этого периода жизни государства позволяет сделать вывод, что Устав о содержащихся под стражей и Общая тюремная инструкция (1915 г.) $[10$, с.122] продолжали существовать в практической деятельности в области исполнения уголовных наказаний, которые дополнялись циркуляром Главного управления местами заключения (ГУМЗ) от 27 апреля 1917 года. Законодательно запрещенные меры телесных наказаний имели лишь формальное запрещение, на практике же не исчезли и применялись тюремным персоналом в силу привычного уклада в обращении с арестантами.

Реформирование тюрем и всей системы отбывания наказаний неизбежно предопределяло изменение всей нормативно-законодательной основы исправительного дела. Органы, исполняющие наказание, в своей практической деятельности руководствовались постановлениями, декретами, директивами, распоряжениями правительства и народного комиссариата юстиции России. 
В основу указанных актов легли основополагающие требования руководства страны того времени, направленные, с одной стороны, на жестокие меры подавления определенных слоев населения, a, с другой стороны, на демократическое, снисходительное отношение к остальной части населения.

В этот период вышли в свет и получили практическую реализацию такие важнейшие законодательные документы, как Временная инструкция о лишении свободы, как мере наказания, и о порядке отбывания такового. Этот документ, изданный народным комиссариатом юстиции 23 июля 1918 года [10, с.129], относится к первым нормативным актам в области исправительнотрудового права советского периода. Указанная инструкция определяла меры дисциплинарного порядка, применяемые к заключенным, нарушающим правила поведения в местах лишения свободы.

В качестве мер дисциплинарного воздействия на осужденных за нарушение существовавшего режима содержания осужденных применялись: выговор наедине или публично; лишение доступа к литературе; лишение права переписки с родственниками; запрещение свиданий, выписки и передач; перевод на уменьшенное питание; водворение в карцер сроком до двух недель; перевод на более строгий режим содержания.

Лица, злостно нарушающие режим содержания, переводились в низший разряд, и срок наказания мог быть продлен. Важным является тот факт, что продление срока уголовного наказания осуществлялось не судом, а решением распределительной комиссии и не за совершение нового преступления, а за злостное нарушение режима содержания, что всегда относилось к разряду дисциплинарных правонарушений.

Взыскания могли накладываться после тщательной проверки по факту нарушения и объяснения провинившегося. Допускалось одновременное наложение нескольких видов взысканий (но не свыше трех) лишь коллегией места заключения, а также условное наложение взысканий.

Таким образом, коллегиальная система определения дисциплинарных наказаний служила гарантией соблюдения прав осужденных, привлекаемых к ответственности, однако вопросы сроков наказания, видов режима содержания, явно относящиеся к компетенции судов, также рассматривались ведомственными формированиями, что исключало, на наш взгляд, соблюдение беспристрастности при решении этих важных вопросов.

Вопросы систематизации пенитенциарного законодательства были самыми актуальными во все исторические периоды. Особенно значимой эта проблема стала в начале 30-х годов XX столетия. Первым законом такого 
направления стал исправительно-трудовой кодекс РСФСР 1924 года [10, с.144]. Вслед за ним последовало принятие и издание исправительно-трудовых кодексов других союзных республик СССР. ИТК 1924 года устранил разнобой в деятельности исправительно-трудовых учреждений, подробно регламентировал вопросы организации режима и применения дисциплинарных мер взыскания в зависимости от особенной личности, социального положения, мотивов правонарушения, поведения, отношения к работе, самостоятельных организаций осужденных.

Защищая права и элементарные свободы осужденных, провозглашая лояльное к ним отношение в местах лишения свободы, исправительно-трудовой кодекс РСФСР предписывал применение таких видов дисциплинарной ответственности за нарушение режима содержания, как изоляция в отдельную камеру сроком до 14 суток, с ежедневной выдачей горячей пищи и выводом на прогулку через два дня на третий (ст. 145). Указанная норма помимо того, что являлась мерой дисциплинарного воздействия за допущенные нарушения, преследовала и цель «устранения влияния худших из наиболее опасных заключенных на остальных» (ст. 8).

В целом же, давая оценку общественной значимости исправительнотрудового кодекса РСФСР 1924 года, представляется необходимым отметить его демократичность и лояльность по отношению к лицам, отбывающим наказания, подход к ним с учетом индивидуальных особенностей и личностных характеристик.

Основные положения исправительно-трудового кодекса РСФСР 1924 года без существенных изменений существовали на протяжении ряда лет. Однако, несмотря на важность этого документа как первого систематизированного нормативного акта в системе исправительного дела России, существовать длительное время без внесения в него поправок он не мог в силу стремительного и постоянно нарастающего ритма общественных преобразований.

Вместе с тем, в рассматриваемый период предполагалось вообще не освобождать из мест лишения свободы тех, кто в период отбывания наказания не встал на путь исправления и продолжал вести вредный, паразитический образ жизни. Такие предложения нашли свое закрепление в некоторых постановлениях ведомственного характера.

Складывающаяся обстановка в местах лишения свободы требовала дополнительной разработки и принятия специальных законодательных актов, 
направленных на стабилизацию правопорядка в исправительно-трудовых учреждениях.

В Постановлении ВЦИК и СНК РСФСР от 26 марта 1928 года «О карательной политике и состоянии мест заключения» $[10$, с.151] было признано необходимым применять суровые меры репрессий в отношении классовых врагов, деклассированных преступников-профессионалов и рецидивистов. Положение об исправительно-трудовых лагерях 1930 года предусматривало дополнительную меру дисциплинарной ответственности, выраженную в изоляции правонарушителей в отдельные помещения на срок до 3 суток.

В начале 50-х годов началась активная изоляция пенитенциарных правонарушителей от основной массы отбывающих наказания с целью исключения их дезорганизующего влияния на других осужденных. Немаловажную роль в вопросе изолированного содержания привычных преступников, особенно преступных авторитетов (воров в законе), сыграли специальные лагеря и штрафные подразделения.

В 1961 году в РСФСР принимается «Положение об исправительнотрудовых колониях МООП РСФСР». Этим документом наряду с новыми видами поощрения осужденных введены и новые виды мер дисциплинарных наказаний: внеочередное дежурство по уборке помещений и территории ИТК; перевод на пониженную норму питания, перевод в помещение камерного типа (ПКТ). Одновременно с этим исключались такие виды дисциплинарных взысканий, как водворение в штрафной изолятор (ШИЗО) до 20 суток с выводом на работу и 15 суток без вывода на работу; водворение в одиночные штрафные камеры до 30 суток; аннулирование ранее начисленных зачетов рабочих дней. [1, с.69].

В некоторых колониях воспитательная работа подменялась административными мерами, взыскания явились главным методом воздействия, причем, администрация делала ставку на самые строгие меры. В своем исследовании Е.Л. Макаров отмечает, что в отдельных подразделениях руководители увлекались водворением осужденных в штрафной изолятор, считая, что наказание тем эффективнее, чем оно суровее, «забывая» об иных формах и методах профилактической работы.[15, с.289].

Исправительно-трудовой кодекс РСФСР 1970 года $\left[\begin{array}{lll}10, & \text { с.170 }\end{array}\right.$ предоставлял право на применение дисциплинарных взысканий, влекущих изменения условий содержания осужденного, начальникам исправительнотрудовых учреждений. 
Вместе с тем, закон предусматривал и взыскания, которые были связаны с переводом осужденного из одного исправительно-трудового учреждения в другое. В ст. 34 Основ (ст. 53 исправительно-трудового кодекса РСФСР) предусматривались случаи возможного перевода из одного исправительнотрудового учреждения в другое, ведущие к тому, что условия содержания становились более суровыми.

Речь идет о переводах из колоний-поселений в колонии общего и строго режимов; из исправительно-трудовых колоний в тюрьму на срок не свыше трех лет с отбыванием оставшейся части срока в положении того вида режима, который ранее устанавливался судом; из воспитательно-трудовой колонии общего режима в воспитательно-трудовую колонию усиленного режима.

Все названные переводы осуществлялись в судебном порядке.

Таким образом, исправительно-трудовой кодекс 1970 года аккумулировал в себе виды взысканий, установленные исправительно- трудовым кодексом РСФСР 1924 года и последующими подзаконными нормативными актами. Кроме того, он дифференцировал дисциплинарную ответственность в зависимости от вида режима исправительно-трудового учреждения. Более суровые меры ответственности предусматривались для лиц, отбывающих наказание в колониях особого режима и тюрьмах.

Таким образом, меры дисциплинарного воздействия на осужденных к лишению свободы на протяжении всей истории развития исправительной системы России занимали важное место среди всей совокупности средств, направленных на достижение целей наказания. Характер этих мер, уровень их правового регулирования и практического применения определялись уровнем развития правовой культуры пенитенциарной науки и практики.

Вопросы совершенствования уголовно-исполнительного законодательства должны, на наш взгляд, опираться на исторический опыт развития системы исполнения наказаний и определяться стоящими перед этой системой задачами.

\section{Список литературы}

1. Епанешников В.С. Дисциплинарные меры воздействия на осужденных к лишению свободы как институт исправительно-трудового права: автореферат дис. ... кандидата юридических наук: 12.00.08. - Москва, - 1993. $25 \mathrm{c}$. 
2. Подосенов О. П. Каторга и ссылка в России в XVI - первой половине XIX вв.: Автореферат дис. на соискание ученой степени кандидата юридических наук. (710) / Моск. гос. ун-т им. М.В. Ломоносова. Юрид. фак. - Москва, - 1971. - 16 с.

3. Монахов В.И. Режим как средство воспитания. Саратов, - 1961. - 205 c.

4. Ширвиндт Е.Г., Утевский Б.С. Советское исправительно-трудовое право / Е. Ширвиндт, Б. Утевский; государственный институт по изучению преступности и преступника. - 2-е изд... - Москва: изд-во Нар. ком. внутр. дел РСФСР, 1931 (тип. изд-ва НКВД). - 255 с.

5. Подобного рода правила существовали, в частности на Сахалинской каторге. Именно в них детализировались указания о режиме отбывания наказания на территории острова (См.: Плотников А.А. Сахалинская политическая каторга и ее антинародная сущность: диссертация ... кандидата юридических наук : 12.00.01. - Москва,1986. - 181 с.).

6. В некоторых германских тюрьмах широко применялся так называемый Engepappest, очень маленький карцер, в котором можно было только стоять или сидеть, но нельзя было ходить или лежать. Пол карцера был выполнен из трехгранных брусьев, обращенных острыми краями вверх. См.: Епанешников В.С. Дисциплинарные меры воздействия на осужденных к лишению свободы как институт исправительно-трудового права: автореферат дис. ... кандидата юридических наук: 12.00.08. - Москва, $-1993 .-25$ с.

7. Гольденвейзер А.С. Современная система наказаний и ее будущность по трудам парижского пенитенциарного конгресса: Приложение к протоколам Киевского Юридического Общества за 1895 г., М. - 2019г. - 136 с.

8. Утевский Б.С. Советская исправительно-трудовая политика [Текст] : учебник для правовых вузов и юридических курсов / Б. С. Утевский ; под ред. зам. дир. Гос. ин-та уголовной политики Б. С. Ошеровича. - Москва : Советское законодательство, - 1934. - 253.

9. ЦГА гор. Москвы. Ф. 474, ОП. 11, д. 8, с. 24.

10. Лосев П.М., Рагулин Г.И.: Сборник нормативных актов по советскому исправительно-трудовому праву (1917-1959 гг.). История законодательства. $360 \mathrm{c}$. 